\title{
Transoral robotic surgery in the management of head and neck tumours
}

Vittorio Rinaldi, Davide Pagani, Sara Torretta and Lorenzo Pignataro

Department of Specialist Surgical Sciences, University of Milan, Otolaryngology Department, Fondazione IRCCS Cà Granda Ospedale Maggiore Policlinico, 20122 Milan, Italy

Correspondence to: Vittorio Rinaldi. Email: rinaldivittorio@yahoo.it

\begin{abstract}
The article reviews the use of robotic technology for head and neck tumours. The authors discuss the development of transoral robotic surgery (TORS), the current status of the technology, and the set-up in the operating room. The article provides a review of the literature, highlighting the applications, advantages, functional outcomes, and disadvantages of TORS for each anatomic subsite (oropharynx, hypopharynx, larynx, parapharyngeal space, and skull base). New challenges related to reconstruction are also presented. Overall early functional and oncologic outcome data are promising; further long-term prospective trials are still needed to confirm the oncological safety of TORS.
\end{abstract}

Keywords: robotic surgery; head and neck surgery; head and neck tumours; transoral surgery.

Published: $26 / 09 / 2013$

Received: 06/03/2013

ecancer 2013, 7:359 DOI: 10.3332/ecancer.2013.359

Copyright: (c) the authors; licensee ecancermedicalscience. This is an Open Access article distributed under the terms of the Creative Commons Attribution License (http://creativecommons.org/licenses/by/3.0), which permits unrestricted use, distribution, and reproduction in any medium, provided the original work is properly cited. 


\section{Introduction}

Robotic-assisted surgery has its roots in 1972, when the National Aeronautics and Space Administration began to investigate a method to provide surgical care to orbiting astronauts through telepresence surgery [1].

After the first laparoscopic splenectomy performed in 1997 [2], robotic-assisted surgery has gained popularity in several surgical specialties such as general, urological, cardiothoracic, gynecological, orthopedic, and neurological surgeries [3].

Transoral robotic surgery (TORS) was first introduced in [4] by Weinstein et al with a case report of a supraglottic laryngectomy in a canine model and by MacLeod and Melder [5], who reported the excision of a vallecular cyst in a human patient with a setup time of 75 min and a surgical time of $30 \mathrm{~min}$. Since these early reports, the development of TORS has been steadily progressing and many other studies on TORS in animal cadavers, human subjects, and various head and neck cancer sites have been published.

In 2006 and 2007, preclinical and clinical studies by a team at the University of Pennsylvania demonstrated [6-8] the feasibility and safety of transoral resections with the assistance of the Da Vinci Surgical Robot (Intuitive Surgical Inc., Sunnyvale, California, United States), such that the US Food and Drug Administration approved TORS for selected benign and malignant head and neck tumours in December 2009 [9].

Because of the possibility of obtaining superior visualisation and complete resection of tumours with wide margins, TORS seems to represent an alternative to open or endoscopic/microscopic approaches in oral and pharyngolaryngeal oncology-particularly with 5-mm instruments - that allows improved vision, greater ease of use, and a shorter operating time [10].

\section{Current robotic system}

The Da Vinci Surgical System consists of three components: a surgeon's console, a patient-side robotic cart equipped with four arms, and a high-definition three-dimensional vision cart. Articulating surgical instruments are mounted on the robotic arms, which are introduced into the upper aerodigestive tract through the mouth of the patient and manipulated remotely with master robot manipulators from the surgeon's console.

As far as head and neck surgery is concerned, usually only three of the four arms are employed: one to handle a 12-mm stereoscopic endoscope at an angle of $0^{\circ}$ or $30^{\circ}$ and the other two equipped with 5-mm endo wrist instruments (Intuitive Surgical Inc.).

Both the endoscope and the robotic instruments are introduced transorally and allow the surgeon to perform procedures equivalent to traditional surgery, with the advantages of enhanced three-dimensional HD visualisation, wide range of motion with seven degrees of freedom, reduction of hand tremors, possibility of navigating around corners through angled scopes, reduction of fatigue, proper handeye coordination, and the possibility of telesurgery and teaching opportunities with more favourable learning curves [3, 11-14].

When compared with open surgical approaches, TORS may avoid disfiguring mandibulotomy; it reduces the need for adjuvant radio and/or chemotherapy and for tracheostomy/gastrostomy, improves the return to normal speech and swallowing, and reduces blood loss and postoperative pain [7, 15-17]. Minimal scarring with reduced risk of wound infection, shorter hospital stays, and shorter recovery times may also improve patients' quality of life (QOL) [18].

TORS may be applied for benign and malignant lesions of the palate, the palatine tonsils, the base of the tongue, the posterior and lateral pharyngeal wall, the parapharyngeal space, the larynx, and the hypopharynx; main contraindications are reduced mouth opening, incomplete lesion visualisation, mandible involvement, tumours involving $>50 \%$ of the base of the tongue or of the posterior pharyngeal wall, internal carotid artery, or prevertebral fascia involvement [7].

\section{Surgical setup}

TORS is defined as the surgery performed through the oral cavity that uses a minimum of three robotic arms and allows bimanual manipulation of tissues. The surgeon's cart should be located at the end of the operating room, allowing free space to manoeuver the surgical cart that is 
placed on the left side of the patient, opposite to the surgeon [19]. The assistant is seated at the head of the patient. The anaesthesia machine and anaesthesiologist are at the patient's foot. After induction, the endoscopic tower and scrub table are placed on the right; the patient should be placed in a strictly supine position on the operating table [14]. The surgeon places a Crow-Davis mouth gag (suspended to the bed) to gain surgical exposure and three sterilely draped robotic arms are placed in surgical position: the instruments (atraumatic forceps and electrocautery spatula tip) are introduced $30^{\circ}$ laterally from the arm supporting the $0^{\circ}$ endoscope and placed in the right and left arms of the robot. In laryngeal and pharyngeal surgeries, a Feyh-Kastenbauer (FK) retractor can be used and a flexible aspiration tube for smoke aspiration is introduced into the nasopharynx through one of the nostrils.

All of the authors stress the importance of the correct positioning of the machine, to allow complete exposition of the lesion and free, unobstructed movements of the robotic arms [3, 11-14].

\section{Oropharynx}

\section{Tongue base}

In 2006, O'Malley et al reported a prospective clinical trial evaluating the use of TORS in three patients with tongue base cancer. They reported an excellent visualisation and tumuor removal possibility. The use of the FK retractor is described to be essential for proper exposure and for instrument manoeuverability. Complete resection with negative surgical margins was achieved in all three cases with an excellent control of bleeding; no intraoperative or postoperative complications were encountered [15].

The use of Da Vinci robot has also been reported for tongue base biopsy in the evaluation of unknown primary tumours of the head and neck [20]. Metha et al reported a retrospective study on ten patients with unknown primary tumours of the head and neck. All patients underwent a cervical biopsy, positron-emission tomography/computed tomography, formal endoscopy, bilateral tonsillectomy, and transoral robotic base of tongue resection. Robot-assisted base of tongue resection identified primary tumours in $90 \%$ patients with minimal morbidity [21].

Reconstruction should be considered particularly for large defects, to maintain a balance between restoration of bulk and maintaining a sensate mucosal surface, so as not to impair the pharyngeal phase of swallowing and to avoid aspiration [22]. The radial forearm flap is the most frequently used [23]. For smaller defects, secondary healing and remucosalisation seem to provide adequate function preservation.

\section{Tonsillar region}

TORS radical tonsillectomy has widened the indications for transoral resection, because TORS allows excellent visualisation in all directions, concurrent tongue base resection, and the possibility of better identifying small and large vessels. In the series of 27 patients presented by Weinstein et al, TORS seems to represent a valid alternative to transmandibular approaches with free-flap reconstruction. All the patients underwent TORS radical tonsillectomy for invasive squamous cell carcinoma (SCC) of the tonsillar region, staged neck dissection, and adjuvant therapy. Major tumour-related contraindications for TORS radical tonsillectomy were: unresectability of involved neck nodes, mandibular invasion, tongue base invasion requiring a resection of $>50 \%$ of the tongue base, pharyngeal wall involvement necessitating resection of $>50 \%$ of the posterior pharyngeal wall, radiological confirmation of carotid artery involvement, and fixation of tumour to prevertebral fascia. Neck dissection was performed one to three weeks following TORS radical tonsillectomy, to avoid the risk of creating a connection between the pharynx and the neck and to avoid additional laryngopharyngeal swelling that might require a tracheotomy. No free-flap reconstruction was needed and the mucosal defect at the end of surgery was allowed to heal by secondary intention. The mean operative time to perform TORS was $1 \mathrm{~h}$ and $43 \mathrm{~min}$ including a mean of $9 \mathrm{~min}$ for exposure and robotic positioning. Complete resection with negative surgical margins was achieved in $93 \%$ of the cases. The surgical complication rate was $19 \%$, most cases resolving without significant sequelae: one mucosal haemorrhage requiring a return to the operating room, one tracheostomy for OSA exacerbation, two cases of trismus, and one of hypernasality requiring an outpatient procedure for correction. No mortality occurred and no cases of pneumonia or fistula were observed. Twenty patients were extubated at the end of the surgical procedure, the remaining six patients remained intubated for laryngopharyngeal swelling, treated with steroids for one to three days and then extubated after an average of 2.7 days postoperatively. One patient required unplanned tracheostomy for his sleep aponea exacerbation. All the patients underwent percutaneous gastrostomy and $96 \%$ of them recovered a proper swallowing function at the follow-up [7]. 
For the majority of the patients, no reconstruction is required if the resection is limited to the tonsillar region; free tissue transfer should be considered in patients predisposed to poor wound healing, or if the carotid artery is exposed in the parapharyngeal space [22]. When the resection involves soft palate tissue, restoring competence of the velopharyngeal sphincter is mandatory; palatal defects involving less than one-quarter can be reconstructed with primary closure or simple approximation to the flap, while more extended defects require soft tissue free flaps, mainly radial forearm, and pharyngeal flaps [24].

\section{Larynx}

Weinstein et al reported a prospective human clinical trial evaluating the use of TORS in three cases of supraglottic partial laryngectomy for supraglottic carcinoma. An excellent surgical exposure with complete tumour resection was achieved. No intraoperative or postoperative complications were reported. The median overall operation time was $120 \mathrm{~min}$ including $18 \mathrm{~min}$ for exposure and robotic positioning. Robotic-assisted supraglottic laryngectomy is reported to be technically feasible and relatively safe, representing an alternative to open approaches and conventional transoral supraglottic partial laryngectomy [8].

Solares and Strome reported three cases of $\mathrm{CO}_{2}$ laser robotic-assisted supraglottic laryngectomy. The FK laryngo-pharyngoscope was reported to provide excellent visualisation in only one patient, and the procedure was completed successfully. In the other two cases, adequate exposure could not be achieved and more traditional techniques were performed [25].

Park et al [26] reported a prospective human trial with four patients with glottic carcinoma successfully treated with TORS; no perioperative complications were reported and all surgical margins were disease free.

\section{Hypopharynx}

Although hypopharyngeal SCC represents a clinically distinct and less frequent entity among other cancers of the head and neck, early experiences using TORS for hypopharyngectomy for I- and II-staged cancers seem to be promising.

Park et al reported a series of ten patients with $\mathrm{T} 1$ or $\mathrm{T} 2$ pyriform sinus and posterior pharyngeal wall cancer successfully treated with TORS. The mean operation time was $62.4 \mathrm{~min}$ with an average of $17.5 \mathrm{~min}$ for the robot setup. No significant perioperative complications were reported. A return to normal swallowing function was observed in all patients within 8.3 days average and decannulation within 6.3 days after surgery. The authors concluded that transoral robotic hypopharyngectomy is feasible and safe for the treatment of early hypopharyngeal tumours [27].

\section{Parapharyngeal space and infratemporal fossa}

TORS used in skull base surgery was first assessed in [28] on animal and cadaver models. They also reported one case of benign neoplasm of the parapharyngeal space and infratemporal fossa treated with TORS. Robotic approach allowed an excellent access, visualisation, and tissue dissection within the parapharyngeal space and infratemporal fossa, providing a safe identification of the internal carotid artery and cranial nerves, and excellent haemostasis. However, certain limitations were observed in the TORS approach, notably its inability to perform wide resection, which may be required for invasive malignant neoplasm. Therefore, the authors concluded that TORS may be best suited for excising well-circumscribed benign lesions, adenomas or schwannomas, and possibly limited parapharyngeal metastatic lymph nodes.

In 2010, the same authors assessed the outcomes of ten patients undergoing parapharyngeal space resection using the TORS approach [29]. The surgery was performed in $90 \%$ of the cases without significant complications, with acceptable operative time and blood loss; one case was converted to an open transcervical approach due to difficulties found during TORS resection. In $70 \%$ of the cases, it was a pleomorphic adenoma and in those patients the reported local control rate was $100 \%$. A decrease of complication rate was noted in TORS when compared with traditional transcervical surgery.

McCool et al [30] reported six complete and two partial dissections of the infratemporal fossa carried out in cadaver models using a suprahyoid port, whereas the second arm and $30^{\circ}$ camera were placed transorally. 
In cadaveric dissections, Hanna et al [31] obtained excellent access to the anterior and central skull base, including the cribriform plate, fovea ethmoidalis, medial orbits, planum sphenoidale, sella turcica, suprasellar and parasellar regions, nasopharynx, pterygopalatine fossa, and clivus.

In skull base surgery, robotic techniques can be considered as the natural evolution of traditional endoscopic techniques [32] and their role is evolving with the goal of maximising surgical resections without compromising oncological principles. Kupferman et al [33] reported using robotic technology to greatly facilitate the suture-based dural reconstruction of the anterior cranial base in a cadaver model, ensuring a minimal trauma to surrounding critical neurovascular structures.

\section{Head and neck robotic reconstructive surgery}

As the application of TORS for the treatment of head and neck cancer increases, robotically assisted reconstruction, whether using free flaps, local flaps, or primary closure, holds the potential of expanding TORS applications, keeping the aim to provide patients with less morbid procedures. The introduction of vascularised tissue into an oropharyngeal defect can provide improved functional recovery. The flexibility of the robotic arms allows suture placement transorally in areas of decreased visibility using traditional open techniques. Even microvascular anastomosis has proved faster and more effective [34]. In robotic-assisted microvascular anastomosis, the robotic arms are placed almost horizontally, in the plane of the bed, and in direct proximity of the external incision; a third arm serves as a stationary assistant, while Black Diamond Micro Needle drivers (Intuitive Surgical) and 9.0 nylon suture are used for the anastomosis [35].

Several case series demonstrated the clinically applicable use of the robot for reconstruction of head and neck.

Mukhija et al [36] described the first two cases of TORS-assisted free flap (radial forearm) reconstruction of orophayrnx and oral cavity: for both cases, the flaps were inset robotically, while the microanastomosis was performed in the standard fashion.

Selber reported robotic-assisted reconstruction in five patients with oropharyngeal tumours: reconstruction included both local and free flaps, depending on the size of the defect, prior radiation, and the presence or absence of a pharyngotomy. The authors reported the first case of robotic anastomosis, with the advantage of tremor elimination, motion scaling up to 5:1, and an enhanced ability to work precisely in confined spaces. There were no oropharyngeal fistulas. Only one postoperative complication was reported; one patient accidentally bit through his pedicle but without resulting flap failure [35]. Genden et al [37] reported a series of 31 patients who underwent TORS reconstruction: promising results are presented with 25 cases of reconstruction with local advancement musculomucosal flap and six with a radial forearm free flap. The authors reported that patients who have been treated with radiation and patients with extensive defects needed free-flap reconstruction because the mucosa was often friable and poorly vascularised. Three patients required a transoral marginal mandibulectomy. All the flaps were inserted robotically, but the anastomosis was done in the standard fashion. None of the patients developed a fistula. Ghanem presented a four-patient case series using robotic free-flap reconstruction. Tumour sites ranged from the tonsil to the base of the tongue and the oral tongue. Three patients received radial forearm free flaps, one a vastus lateralis free flap. All the flaps were inset robotically, with manual microvascular anastomosis. No fistulas were reported, but complications consisted of one neck infection and one partial dehiscence at the anterior tonsillar pillar (allowed to heal by secondary intention) [38].

Longfield et al performed 20 robot-assisted oropharyngeal reconstructions, including six anterolateral thigh flaps, five radial forearm flaps, two ulnar artery perforator flaps, two FAMM flaps, five buccal or pharyngeal transposition flaps. Robotic microvascular anastomosis was performed in four of these cases. No flap losses were described [34].

Song et al reported a case series of five patients who underwent robotic free-flap reconstruction (four radial forearm free flap and one anterolateral thigh free flap) after TORS for oropharynx tumours. In one case, the microanastomosis was performed using the robotic arms. No major complications were encountered, including flap failure, haematoma, or wound dehiscence [39].

Longfield et al provided an algorithmic approach to determine the need of reconstruction after robotic excision of head and neck tumours. TORS is not routinely necessary for tumours within the oral cavity, which usually offer a good manual transoral access. Retromolar trigone represents the only exception and, because of its anatomical features, tumours of this region may benefit from TORS resection and reconstruction: in these cases, local flaps are usually sufficient for reconstruction. Tumours of the oropharynx (tonsil, base of the tongue, and soft palate) are an ideal indication for TORS resection: complicated excisions (involving carotid sheath exposure, bone exposure, and so on) 
with resulting large defect may benefit from microvascular reconstruction. For supraglottic larynx, Longfield et al [34] considered that the reconstruction with free flap is often impractical, although in patients with a good oral aperture, it is technically feasible to resect robotically tumours in the supra- and infrahyoid regions.

\section{Functional outcomes of TORS}

Early TORS data support impressive functional outcomes with low rates of gastrostomy dependency, prompt decannulation, and resumption of normal oral intake (Table 1).

Table 1. Functional outcomes of TORS.

\begin{tabular}{|c|c|c|c|c|c|}
\hline Author & Primary site & $\begin{array}{c}\text { Number of } \\
\text { patients }\end{array}$ & $\begin{array}{l}\text { Complications } \\
\text { rate (\%) }\end{array}$ & $\begin{array}{c}\text { Tracheostomy } \\
\text { (\%) }\end{array}$ & $\begin{array}{c}\text { Gastrostomy } \\
\text { Tube (\%) }\end{array}$ \\
\hline & Palatine tonsil & 27 & & & \\
\hline & Base of tongue & 11 & & & \\
\hline Hurtuk et al, 2011 & Larynx & 4 & 0 & 0 & 17 \\
\hline \multirow[t]{5}{*}{ [42] } & Retromolar trigone & 1 & & & \\
\hline & Parapharynx & 1 & & & \\
\hline & Total & 44 & & & \\
\hline & Tonsil & 7 & & & \\
\hline & Base of tongue & 3 & & & \\
\hline Genden et al, 2009 & Parapharynx & 2 & 0 & 0 & 0 \\
\hline \multirow[t]{4}{*}{ [16] } & Hypopharynx & 4 & & & \\
\hline & Palate & 2 & & & \\
\hline & Total & 18 & & & \\
\hline & Oropharynx & 18 & & & \\
\hline Hans et al, 2011 & Larynx & 5 & 4,5 & 0 & 9 \\
\hline \multirow[t]{3}{*}{ [49] } & Hypopharynx & 2 & & & \\
\hline & Total & 25 & & & \\
\hline & Oropharynx & 44 & & & \\
\hline Vergez et al, 2012 & Hypopharynx & 64 & 20,6 & 15 & nd \\
\hline \multirow[t]{3}{*}{ [50] } & Larynx & 18 & & & \\
\hline & Total & 126 & & & \\
\hline & Pharynx & 2 & & & \\
\hline Remacle et al, 2012 & Supraglottic & 2 & 0 & 0 & nd \\
\hline [51] & Total & 4 & & & \\
\hline Weinstein et al, 2007 [7] & Oropharynx & 27 & 14.8 & 3.7 & 4 \\
\hline \multirow[t]{2}{*}{ Park et al, 2009 [52] } & Tonsil & 5 & 0 & 100 & 0 \\
\hline & Tonsil & 19 & & & \\
\hline Moore et al, 2009 & Base of tongue & 26 & 8,9 & 31,1 & 17,8 \\
\hline [41] & Total & 45 & & & \\
\hline
\end{tabular}


ecancer $2013,7: 359$

Table 1. Continued.

\begin{tabular}{|c|c|c|c|c|c|}
\hline & Supraglottic & 10 & & & \\
\hline Lawson et al, 2011 & Pharynx & 10 & 0 & 0 & nd \\
\hline \multirow[t]{5}{*}{ [19] } & Oral cavity & 4 & & & \\
\hline & Total & 24 & & & \\
\hline & Aryepiglottic fold & 3 & & & \\
\hline & Piriform sinus & 2 & & & \\
\hline & Pharynx & 5 & & & \\
\hline Aubry et al, 2011 & Base of tongue & 3 & nd & 11,8 & 11,8 \\
\hline \multirow[t]{4}{*}{ [53] } & Vallecula & 1 & & & \\
\hline & Epiglottis & 2 & & & \\
\hline & Arytenoid & 2 & & & \\
\hline & Total & 17 & & & \\
\hline \multirow[t]{2}{*}{ Weinstein et al, 2010 [43] } & Oropharynx & 47 & 12,8 & 10,6 & 2,4 \\
\hline & Supraglottic 2 & 2 & & & \\
\hline Benazzo et al, 2012 & Oropharynx & 4 & 16,7 & 100 & 0 \\
\hline [54] & Total & 6 & & & \\
\hline Iseli et al 2009 & Oropharynx & 33 & & & \\
\hline \multirow[t]{4}{*}{ [40] } & Larynx & 12 & 31,5 & 9,3 & 16,7 \\
\hline & Oral cavity & 6 & & & \\
\hline & Hypopharynx & 3 & & & \\
\hline & Total & 54 & & & \\
\hline Sinclair et al, 2011 & Tonsil & 29 & & & \\
\hline \multirow[t]{2}{*}{ [55] } & Base of tongue & 13 & 0 & 0 & 10 \\
\hline & Total & 42 & & & \\
\hline
\end{tabular}

Genden et al [16] reported the ability to tolerate an oral diet at a mean of 1.4 days after surgery without any patients requiring gastrostomy tubes. Iseli et al reported that $83 \%$ patients were tolerating an oral diet within 14 days, while $17 \%$ required a feeding tube at 12 -month follow-up, and $5.6 \%$ demonstrated signs or symptoms of aspiration [37]. Moore et al reported that $82 \%$ of the patients were tolerating oral diet by the first postoperative visit, whereas $17 \%$ required a feeding tube, and none required assistance with feeding at one-year follow-up [38]. Hurtuk et al reported that $100 \%$ of the patients were able to return to oral diet on the day of surgery and $20 \%$ of them required feeding tubes mainly for adjuvant therapy [39].

The majority of the authors reported a low rate of tracheotomy for patients undergoing TORS (see Table 1 for details). Moreover, most of those patients were decannulated within two weeks and no patients required tracheotomy tube at one year after surgery [13].

\section{Oncological outcomes of TORS}

The oncological outcomes from TORS are slowly emerging in the literature and they seem promising [13] (Table 2). In the cohort study, on 47 patients with advanced oropharyngeal carcinoma treated with TORS, Weinstein et al reported a local recurrence rate of $2 \%$, a regional recurrence rate of $4 \%$, and a distance recurrence rate of $9 \%$ at a minimum of 18 months of follow-up. Overall survival rates were $96 \%$ at 
one year and $82 \%$ at two years, with a disease-specific survival of $98 \%$ at one year and $90 \%$ at two years. The disease-free survival was $96 \%$ at one year and $79 \%$ at two years. Extracapsular extension in the metastatic nodal disease was found to be statistically affecting the overall survival rates, $38 \%$ of the patients avoided chemotherapy and, because of the high rate of negative margins, $11 \%$ did not receive adjuvant chemoradiotherapy [40].

Table 2. Oncological outcomes of TORS.

\begin{tabular}{|c|c|c|c|c|c|}
\hline Author & Primary site & $\begin{array}{l}\text { Number of } \\
\text { patients }\end{array}$ & $\begin{array}{l}\text { Follow up } \\
\text { (months) }\end{array}$ & $\begin{array}{c}\text { Overall } \\
\text { survival (\%) }\end{array}$ & $\begin{array}{c}\text { Free of } \\
\text { disease (\%) }\end{array}$ \\
\hline & Palatine tonsil & 27 & & & \\
\hline & Base of tongue & 11 & & & \\
\hline Hurtuk et al, 2011 & Larynx & 4 & $16,3 \pm 7,5$ & 100 & 97 \\
\hline \multirow[t]{5}{*}{ [42] } & Retromolar trigone & 1 & & & \\
\hline & Parapharynx & 1 & & & \\
\hline & Total & 44 & & & \\
\hline & Tonsil & 7 & & & \\
\hline & Base of tongue & 3 & & & \\
\hline Genden et al, 2009 & Parapharynx & 2 & 5,1 & 100 & 100 \\
\hline \multirow[t]{4}{*}{ [16] } & Hypopharynx & 4 & & & \\
\hline & Palate & 2 & & & \\
\hline & Total & 18 & & & \\
\hline & Oropharynx & 18 & & & \\
\hline Hans et al, 2011 & Larynx & 5 & 20,6 & 100 & 100 \\
\hline \multirow[t]{3}{*}{ [49] } & Hypopharynx & 2 & & & \\
\hline & Total & 25 & & & \\
\hline & Oropharynx & 44 & & & \\
\hline Vergez et al, 2012 & Hypopharynx & 64 & nd & 98,4 & nd \\
\hline \multirow[t]{3}{*}{ [50] } & Larynx & 18 & & & \\
\hline & Total & 126 & & & \\
\hline & Pharynx & 2 & & & \\
\hline Remacle et al, 2012 & Supraglottic & 2 & 9 & 100 & 100 \\
\hline \multirow[t]{2}{*}{ [51] } & Total & 4 & & & \\
\hline & Tonsil & 19 & & & \\
\hline Moore et al, 2009 & Base of tongue & 26 & $1-16$ & 97,8 & 91,1 \\
\hline \multirow[t]{2}{*}{ [41] } & Total & 45 & & & \\
\hline & Supraglottic & 10 & & & \\
\hline Lawson et al, 2011 & Pharynx & 10 & 17 & nd & 91,7 \\
\hline \multirow[t]{2}{*}{ [19] } & Oral cavity & 4 & & & \\
\hline & Total & 24 & & & \\
\hline
\end{tabular}


ecancer $2013,7: 359$

Table 2. Continued.

\begin{tabular}{|c|c|c|c|c|c|}
\hline & Aryepiglottic fold & 3 & & & \\
\hline & Piriform sinus & 2 & & & \\
\hline & Pharynx & 5 & & & \\
\hline Aubry et al, 2011 & Base of tongue & 3 & 6,5 & 100 & 100 \\
\hline \multirow[t]{4}{*}{ [53] } & Vallecula & 1 & & & \\
\hline & Epiglottis & 2 & & & \\
\hline & Arytenoid & 2 & & & \\
\hline & Total & 17 & & & \\
\hline \multirow[t]{2}{*}{ Weinstein et al, 2010 [43] } & Oropharynx & 47 & $18-44$ & 82 & 79 \\
\hline & Supraglottic 2 & 2 & & & \\
\hline Benazzo et al, 2012 & Oropharynx & 4 & 5,8 & 100 & 100 \\
\hline \multirow[t]{2}{*}{ [54] } & Total & 6 & & & \\
\hline & Oral cavity & 2 & & & \\
\hline White et al, 2010 & Oropharynx & 77 & 26 & 100 & 86.5 \\
\hline \multirow[t]{2}{*}{ [45] } & Larynx & 10 & & & \\
\hline & Total & 89 & & & \\
\hline
\end{tabular}

Cohen et al reported the outcome profile of oropharyngeal SCC treated with TORS comparing two different groups of patients: HPV-positive and negative. In the HPV-positive group (37 patients), the authors reported no local or regional recurrence, though two patients had distant recurrences. In the HPV-negative group, there were no local recurrence, one patient had both regional and distant recurrences. Survival rates showed no statistically significant differences between the two groups of patients, with $81 \%$ in HPV-positive group and $80 \%$ in the HPV-negative group [41].

White et al in a prospective case study of 89 patients with head and neck SCC of all stages and subsites treated with TORS, reported at a median follow-up period of 26 months three patients with local recurrence, seven with regional recurrence (two of whom also had distant metastases), and one patient with distant recurrence; seven patients were treated with TORS for recurrent disease. Of the patients who underwent TORS as primary treatment, $63 \%$ underwent adjuvant radiotherapy and $48 \%$ had chemotherapy either before or after surgery; $8 \%$ underwent salvage TORS after primary chemoradiotherapy. At the last follow-up visit, 82 patients had no evidence of disease, one died of the disease, two died of other diseases, and four were alive with disease. The overall two-year recurrence free survival rate was $86.3 \%$ [42].

Genden et al in a prospective case-control study of 30 patients with head and neck SCC of all stages and subsites treated with TORS and adjuvant therapy, reported 24 patients alive with no recurrent disease at last follow-up visit. Two patients had local recurrence, two developed distant recurrence, and one developed a second primary tumour. The 18-month locoregional control, distant control, disease-free survival, and overall survival reported rates of $91 \%, 93 \%, 78 \%$, and $90 \%$, respectively [17].

\section{QOL after TORS}

Even if the most important outcome for cancer patients is overall survival, in patients with head and neck cancer, QOL, and functional outcome may really be affected by psychological impact of loss of function and physical disfigurement. This has led to a shift to not only organ-preservation treatments, but also function-preservation treatments. Frequent problems include difficulty with speech, respiration, and eating [13]. Leonhardt et al reported a return to normal swallowing function and diet one year after surgery in 38 patients with oropharyngeal 
SCC treated with TORS, while the speech domain was significantly reduced even one year after surgery. They reported that patients who had TORS followed by chemoradiation had significantly lower swallowing scores compared with those without [43].

The case control study on 30 patients with head and neck SCC reported by Genden et al found that patients treated with TORS had significantly better short-term swallowing and eating ability and diet compared with patients treated with primary chemoradiation. While TORS patients had a return to baseline in all domains (swallowing, eating, and diet) at 12 months, patients who had chemoradiotherapy did not have a return to baseline in the diet domain [17].

In a cohort of 64 patients who underwent TORS for benign and malignant lesions of the head and neck region, Hurtuk et al observed the resumption of normal oral intake in all but one patient, with no patients who needed tracheostomy. Although in all of the patients, the selfadministered QOL questionnaire underlined a postoperative decreasing in all of the values, at the one-year follow-up the major part of them returned back to high domains, with the exception of eating function and attitude. QOL scores differed significantly among patients who underwent TORS for malignant diseases compared with those who had a robotic resection for benign lesions; similarly, QOL scores were significantly lower for those patients who underwent adjuvant radio- or chemotherapy and in those affected by tonsillar region cancer [18].

The overall hospital stay is reported to be shorter for TORS patients than for those who would have otherwise undergone an open approach. In the case series of Moore et al, all the 35 patients were discharged from the hospital within six days [38]; in the study of Boudreaux et al, the mean hospital stay reported was 2.6 days [44], whereas in the experience of Weinstein et al, it was between five and seven days [15, 45].

\section{Conclusions}

Development of TORS has greatly facilitated the minimally invasive surgical approach for head and neck carcinoma, circumventing many of the technical limitations commonly associated with transoral laser microsurgical techniques, such as line of sight and twohanded surgery.

TORS provides superb three-dimensional visualisation and magnification in all directions, with tremor filtration, greater freedom of instrument movement facilitating delicate dissection, minimally invasive and less morbid access, and the ability of two surgeons to operate within the field. The excellent ability of bleeding control facilitates en bloc complete tumour resection. Technical feasibility, efficacy, and safety have been largely demonstrated by many studies. In patients undergoing TORS, shorter operative time and decreased hospital stay have been observed; excellent oncological and functional outcomes have been also reported [43]. Faster return to normal function allows patients to begin adjuvant therapy, if warranted, much sooner than in patients who undergo open surgery [39], affording potential advantages, and benefits over current treatment modalities of head and neck tumours.

Not all the patients are good candidates for TORS because some of them may present some limiting factors, mostly affecting proper surgical exposure, such as trismus, narrow arched mandible, full dentition, and retrognathia [42]. Access to the tumour may also be influenced by the site and the extension of the tumour, and the equipment employable by the surgeon [16].

The bigger limitation of robotic technology seems to be represented by the absence of sensory tactile feedback, which may give significant drawback in a number of situations [12]. The initial cost of approximately US $\$ 1.5$ million (coupled with an approximately US $\$ 100,000$ yearly maintenance fee and US $\$ 200 /$ case/disposable instrument) is a significant financial investment and it may clearly hinder widespread use. However, the benefits of decreased operative time and decreased length of hospital stay could offset this cost [45]. Operating room setup time and surgical time can be significantly long at the beginning, but all published articles demonstrated a precipitously and significant reduction of those times as the surgeons gained experience with the Da Vinci Surgical System [42] (Table 3).

In terms of the teachability of TORS, training programs have already yielded successes [45]. As for as oncological results, the evaluations of the surgical margins seem to confirm that the Da Vinci Surgical System may provide, with an accurate patient selection, complete tumour resection with preservation of swallowing function in the majority of cases. 
Table 3. TORS operating room setup and surgical times.

\begin{tabular}{|c|c|c|c|c|}
\hline Author & Primary site & $\begin{array}{l}\text { Number of } \\
\text { patients }\end{array}$ & $\begin{array}{l}\text { Set-up time (min) } \\
\text { Range (average) }\end{array}$ & $\begin{array}{l}\text { Operative time (min) } \\
\text { Range (average) }\end{array}$ \\
\hline & Tonsil & 7 & & \\
\hline & Base of tongue & 3 & & \\
\hline Genden et al, 2009 & Parapharynx & 2 & $20-140(54,6)$ & $45-150(84,0)$ \\
\hline \multirow[t]{4}{*}{ [16] } & Hypopharynx & 4 & & \\
\hline & Palate & 2 & & \\
\hline & Total & 18 & & \\
\hline & Oropharynx & 18 & & \\
\hline Hans et al, 2011 & Larynx & 5 & $15-100(25,0)$ & $20-150(70,0)$ \\
\hline \multirow[t]{3}{*}{ [49] } & Hypopharynx & 2 & & \\
\hline & Total & 25 & & \\
\hline & Oropharynx & 44 & & \\
\hline Vergez et al, 2012 & Hypopharynx & 64 & $52 \pm 46$ & $90 \pm 92$ \\
\hline \multirow[t]{3}{*}[50]{} & Larynx & 18 & & \\
\hline & Total & 126 & & \\
\hline & Pharynx & 2 & & \\
\hline Remacle et al, 2012 & Supraglottic & 2 & $10-60(30,0)$ & $60-125(94,0)$ \\
\hline$[51]$ & Total & 4 & & \\
\hline Weinstein et al, 2007 [7] & Oropharynx & 27 & $2-22(9,0)$ & $26-233(84,0)$ \\
\hline \multirow[t]{2}{*}{ Park et al, 2009 [52] } & Tonsil & 5 & $15-25(19,0)$ & $40-50(44,0)$ \\
\hline & Tonsil & 19 & $54-59(68,6)$ first 10 & $45-320(71,8)$ first 10 \\
\hline \multirow[t]{3}{*}{ Moore et al, 2009 [41] } & Base of tongue & 26 & $14-28(22,3)$ other 35 & $6-309(71,3)$ other 35 \\
\hline & Total & 45 & $14-59(32,6)$ total & $6-320(71,4)$ total \\
\hline & Supraglottic & 10 & & \\
\hline \multirow[t]{6}{*}{ Lawson et al, 2011 [19] } & Pharynx & 10 & $10-60(24,0)$ & $12-180(67,0)$ \\
\hline & Oral cavity & 4 & & \\
\hline & Total & 24 & & \\
\hline & Aryepiglottic fold & 3 & & \\
\hline & Piriform sinus & 2 & & \\
\hline & Pharynx & 5 & & \\
\hline Aubry et al, 2011 & Base of tongue & 3 & $10-50(20,5)$ & $10-90(39,7)$ \\
\hline \multirow[t]{5}{*}{ [53] } & Vallecula & 1 & & \\
\hline & Epiglottis & 2 & & \\
\hline & Arytenoid & 2 & & \\
\hline & Total & 17 & & \\
\hline & Supraglottic 2 & 2 & & \\
\hline Benazzo et al, 2012 & Oropharynx & 4 & nd & $35-135(70,8)$ \\
\hline$[54]$ & Total & 6 & & \\
\hline
\end{tabular}


In conclusion, TORS has proven to be a safe and feasible treatment for tumours of the upper aerodigestive tract, and its continuing use and development is encouraged; the results of the published articles are still not sufficient to validate the oncological safety of TORS and further long-term prospective trials are still needed to confirm those results.

\section{References}

1. Camarillo DB, Krummel TM and Salisbury JK Jr (2004) Robotic technology in surgery: past, present, and future Am J Surg 188 (4A Suppl) 2S-15S DOI: 10.1016/j.amjsurg.2004.08.025 PMID: 15476646

2. Gorey TF and Bonadio F (1997) Laparoscopic-assisted surgery Semin Laparosc Surg 4(2) 102-9 PMID: 10401147

3. Genden EM et al (2012) Transoral robotic surgery: role in the management of upper aerodigestive tract tumors Head Neck 34(6) 886-93 DOI: 10.1002/hed.21752 PMID: 22610591

4. Weinstein GS et al (2005) Transoral robotic surgery: supraglottic laryngectomy in a canine model Laryngoscope 115(7) 1315-9 DOI: 10.1097/01.MLG.0000170848.76045.47 PMID: 15995528

5. McLeod IK and Melder PC (2005) Da Vinci robot-assisted excision of a vallecular cyst: a case report Ear Nose Throat J 84(3) 170-2 PMID: 15871586

6. Hockstein NG, O'Malley BW Jr and Weinstein GS (2006) Assessment of intraoperative safety in transoral robotic surgery Laryngoscope 116(2) 165-8 DOI: 10.1097/01.mlg.0000199899.00479.75 PMID: 16467698

7. Weinstein GS et al (2007) Transoral robotic surgery: radical tonsillectomy Arch Otolaryngol Head Neck Surg 133(12) 1220-6 DOI: 10.1001/archotol.133.12.1220 PMID: 18086963

8. Weinstein GS et al (2007) Transoral robotic surgery: supraglottic partial laryngectomy Ann Otol Rhinol Laryngol 116(1) 19-23 PMID: 17305273

9. Weinstein G and O'Malley BW Jr (2009) FDA Clears Transoral Robotic Surgery-Developed at Penn-for Tumors of Mouth, Throat and Voice Box http://www.uphs.upenn.edu/news/News Releases/2009/12/rors-robotic head-neck-surgery/

10. O'Malley BW Jr, Weinstein GS and Hockstein NG (2006) Transoral robotic surgery (TORS): glottic microsurgery in a canine model J Voice 20 263-8 DOI: 10.1016/j.jvoice.2005.10.004

11. Oliveira CM et al (2012) Robotic surgery in otolaryngology and head and neck surgery: a review Minim Invasive Surg Epub 2012 Apr 10 DOI: 10.1155/2012/286563 PMID: 22567225 PMCID: $\underline{3337488}$

12. Garg A et al (2010) Robotic surgery in head and neck cancer: a review Oral Oncol 46(8) 571-6 DOI: 10.1016/j.oraloncology.2010.04.005 PMID: 20542723

13. de Almeida JR and Genden EM (2012) Robotic surgery for oropharynx cancer: promise, challenges, and future directions Curr Oncol Rep 14(2) 148-57 DOI: 10.1007/s11912-012-0219-y PMID: 22311683

14. Hans S et al (2012) Transoral robotic surgery in head and neck cancer Eur Ann Otorhinolaryngol Head Neck Dis 129(1) 32-7 DOI: 10.1016/j.anorl.2011.06.003

15. O'Malley BW et al (2006) Transoral robotic surgery (TORS) for base of the tongue neoplasms Laryngoscope 116(8) 1465-72 DOI: $10.1097 / 01 . \mathrm{mlg} .0000227184 .90514 .1 \mathrm{a}$

16. Genden EM, Desai S and Sung CK (2009) Transoral robotic surgery for the management of head and neck cancer: a preliminary experience Head Neck 31(3) 283-9 DOI: 10.1002/hed.20972 
17. Genden EM et al (2011) Transoral robotic resection and reconstruction for head and neck cancer Laryngoscope 121 1668-74 DOI: $\underline{10.1002 / l a r y .21845}$ PMID: 21792953

18. Hurtuk AM et al (2011) Quality-of-life outcomes in transoral robotic surgery Otolaryngol Head Neck Surg 146(1) 68-73 DOI: 10.1177/0194599811421298 PMID: 21881053

19. Lawson $\mathrm{G}$ et al (2011) Transoral robotic surgery for the management of head and neck tumors: learning curve Eur Arch Otorhinolaryngol 268(12) 1795-801 DOI: 10.1007/s00405-011-1537-7 PMID: 21365213

20. Abuzeid WM, Bradford CR and Divi V (2011) Transoral robotic biopsy of the tongue base: a novel paradigm in the evaluation of unknown primary tumors of the head and neck Head Neck doi: 10.1002/hed.21968 DOI: 10.1002/hed.21968 PMID: 22180229

21. Mehta $V$ et al (2012) A new paradigm for the diagnosis and management of unknown primary tumors of the head and neck: a role for transoral robotic surgery Laryngoscope DOI: 10.100 PMID: 23154813

22. de Almeida JR, Park RC and Genden EM (2012) Reconstruction of transoral robotic surgery defects: principles and techniques J Reconstr Microsurg 28 465-72 DOI: 10.1055/s-0032-1313762 PMID: 22744899

23. O'Connell DA et al (2008) Swallowing function in patients with base of tongue cancers treated with primary surgery and reconstructed with a modified radial forearm flap Arch Otolaryngol Head Neck Surg 134(8) 857-64 DOI: 10.1001/archotol.134.8.857

24. Seikaly $\mathrm{H}$ et al (2008) Functional soft palate reconstruction: a comprehensive surgical approach Head Neck $301615-23$ DOI: 10.1002/hed.20919 PMID: 18798302

25. Solares CA and Strome $\mathrm{M}$ (2007) Transoral robot-assisted $\mathrm{CO}_{2}$ laser supraglottic laryngectomy: experimental and clinical data Laryngoscope 117(5) 817-20 DOI: 10.1097/MLG.0b013e31803330b7 PMID: $\underline{17473675}$

26. Park YM et al (2009) Transoral robotic surgery (TORS) in laryngeal and hypopharyngeal cancer J Laparoendosc Adv Surg Tech A 19(3) 361-8 DOI: 10.1089/lap.2008.0320 PMID: 19405798

27. Park YM et al (2010) Feasibility of transoral robotic hypopharyngectomy for early-stage hypopharyngeal carcinoma Oral Oncol 46(8) 597-602 DOI: 10.1016/j.oraloncology.2010.05.003 PMID: 20619721

28. O'Malley BW Jr and Weinstein GS (2007) Robotic skull base surgery: preclinical investigations to human clinical application Arch Otolaryngol Head Neck Surg 133(12) 1215-19 DOI: 10.1001/archotol.133.12.1215

29. O'Malley BW Jr et al (2010) Transoral robotic surgery for parapharyngeal space tumors Orl J Otorhinolaryngol Relat Spec 72(6) 332-6 DOI: $10.1159 / 000320596$

30. McCool RR et al (2010) Robotic surgery of the infratemporal fossa utilizing novel suprahyoid port Laryngoscope 120(9) 1738-43 DOI: 10.1002/lary.21020 PMID: 20583114

31. Hanna EY et al (2007) Robotic endoscopic surgery of the skull base: a novel surgical approach Arch Otolaryngol Head Neck Surg 133(12) 1209-14 DOI: 10.1001/archotol.133.12.1209 PMID: 18086961

32. Dallan I et al (2011) The natural evolution of endoscopic approaches in skull base surgery: robotic-assisted surgery? Acta Otorhinolaryngol Ital 31(6) 390-4 PMID: $\underline{3272867}$

33. Kupferman ME et al (2011) Feasibility of a robotic surgical approach to reconstruct the skull base Skull Base 21(2) 79-82 DOI: 10.1055/s-0030-1261258

34. Longfield EA, Holsinger FC and Selber JC (2012) Reconstruction after robotic head and neck surgery: when and why $J$ Reconstr Microsurg 28 445-9 DOI: 10.1055/s-0032-1306376 PMID: 22399257 
35. Selber JC (2010) Transoral robotic reconstruction of oropharyngeal defects: a case series Plast Reconstr Surg 126(6) 1978-87 DOI: $\underline{10.1097 / P R S .0 b 013 e 3181 f 448 e 3}$ PMID: 21124136

36. Mukhija VK et al (2009) Transoral robotic assisted free flap reconstruction Orl-Head Neck Surg 140(1) 124-5 DOI: 10.1016/j. otohns.2008.09.024

37. Genden EM et al (2011) The role of reconstruction for transoral robotic pharyngectomy and concomitant neck dissection Arch Otolaryngol Head Neck Surg 137(2) 151-6 DOI: 10.1001/archoto.2010.250 PMID: 21339401

38. Ghanem TA (2011) Transoral robotic-assisted microvascular reconstruction of the oropharynx Laryngoscope 121(3) 580-2 DOI: 10.1002/lary.21428 PMID: 21344439

39. Song HG et al (2013) Robot-assisted free flap in head and neck reconstruction Arch Plast Surg 40(4) 353-8 DOI: 10.5999/ aps.2013.40.4.353 PMID: 23898431 PMCID: $\underline{3723995}$

40. Iseli TA et al (2009) Functional outcomes after transoral robotic surgery for head and neck cancer Otolaryngol Head Neck Surg 141(2) 166-71 DOI: 10.1016/j.otohns.2009.05.014 PMID: 19643246

41. Moore EJ, Olsen KD and Kasperbauer JL (2009) Transoral robotic surgery for oropharyngeal squamous cell carcinoma: a prospective study of feasibility and functional outcomes Laryngoscope 119(11) 2156-64 DOI: 10.1002/lary.20647 PMID: 19824067

42. Hurtuk A et al (2011) Outcomes of transoral robotic surgery: a preliminary clinical experience Otolaryngol Head Neck Surg 145(2) 248-53 DOI: 10.1177/0194599811402172 PMID: 21810777

43. Weinstein GS et al (2010) Transoral robotic surgery for advanced oropharyngeal carcinoma Arch Otolaryngol Head Neck Surg 136(11) 1079-85 DOI: 10.1001/archoto.2010.191 PMID: 21079160

44. Cohen MA et al (2011) Transoral robotic surgery and human papillomavirus status: Oncologic results Head Neck 33(4) 573-80 DOI: 10.1002/hed.21500 PMID: 21425382

45. White HN et al (2010) Transoral robotic-assisted surgery for head and neck squamous cell carcinoma: one- and 2-year survival analysis Arch Otolaryngol Head Neck Surg 136(12) 1248-52 DOI: 10.1001/archoto.2010.216 PMID: 21173375

46. Leonhardt FD et al (2012) Transoral robotic surgery for oropharyngeal carcinoma and its impact on patient-reported quality of life and function Head Neck 34(2) 146-54 DOI: 10.1002/hed.21688

47. Boudreaux BA et al (2009) Robot-assisted surgery for upper aerodigestive tract neoplasms Arch Otolaryngol Head Neck Surg 135(4) 397-401 DOI: 10.1001/archoto.2009.24 PMID: 19380364

48. Weinstein GS et al (2009) Transoral robotic surgery: does the ends justify the means? Curr Opin Otolaryngol Head Neck Surg 17(2) 126-31 DOI: 10.1097/MOO.0b013e32832924f5 PMID: 19342953

49. Hans S et al (2012) Transoral robotic surgery for head and neck carcinomas Eur Arch Otorhinolaryngol 269(8) 1979-84 DOI: 10.1007/s00405-011-1865-7

50. Vergez $\mathrm{S}$ et al (2012) Initial multi-institutional experience with transoral robotic surgery Otolaryngol Head Neck Surg 147(3) 475-81 DOI: 10.1177/0194599812443221 PMID: 22473832

51. Remacle $\mathrm{M}$ et al (2012) Combining a new $\mathrm{CO}_{2}$ laser wave guide with transoral robotic surgery: a feasibility study on four patients with malignant tumors Eur Arch Otorhinolaryngol 269(7) 1833-7 DOI: 10.1007/s00405-011-1822-5

52. Park YM et al (2009) Feasibility of transoral lateral oropharyngectomy using a robotic surgical system for tonsillar cancer Oral Oncol 45(8) e62-6 DOI: 10.1016/j.oraloncology.2009.02.012 PMID: 19442570 
53. Aubry K et al (2011) Transoral robotic surgery for head and neck cancer: a series of 17 cases Eur Ann Otorhinolaryngol Head Neck Dis 128(6) 290-6 DOI: 10.1016/j.anorl.2011.05.002 PMID: 21955463

54. Benazzo M, Canzi P and Occhini A (2012) Transoral robotic surgery with laser for head and neck cancers: a feasibility study Orl J Otorhinolaryngol Relat Spec 74(3) 124-8 DOI: 10.1159/000337092 PMID: 22473107

55. Sinclair CF et al (2011) Patient-perceived and objective functional outcomes following transoral robotic surgery for early oropharyngeal carcinoma Arch Otolaryngol Head Neck Surg 137(11) 1112-6 DOI: 10.1001/archoto.2011.172 PMID: 22106235 